Textures and Microstructures, 1991, Vols 14-18, pp. 1245-1250 Reprints available from the publisher

Photocopying permitted by license only
(C) 1991 Gordon and Breach Science Publishers SA Printed in the United Kingdom

\title{
INFLUENCE OF COLD ROLLING WITH GROOVED ROLLS ON THE TEXTURE FORMATION OF STEEL SHEETS
}

\author{
KATSUMI TANIKAWA, YOSHIHIRO HOSOYA and AKIHIKO NISHIMOTO
}

Steel Research Center, NKK Corporation, 1 Kokan-cho, Fukuyama, Hiroshima, Japan

\section{Abstract}

Effects of cold rolling with grooved rolls and following flattening on both the cold rolling texture and the primary recrystallization texture of extra low carbon Al-killed steel sheets have been studied by crystallite orientation distribution function (ODF) analysis. Consequently, it was clarified that the preferred orientation of the sheet subjected to the groove-rolling followed by flattening shifted from $\{112\}<111\rangle$ to $\{100\}<011\rangle$. With change in the cold rolling texture, the primary recrystallization texture of the groove-rolled sheet was composed of lower $\{111\}\langle 110\rangle$ and higher $\{100\}\langle 0 \mathrm{vw}\rangle$ as compared with that of the conventionally flat rolled one. The results suggest that the lattice rotation around $\langle 110\rangle$ axis which is parallel to the transverse direction is accelerated by the groove-rolling.

\section{INTRODUCTION}

As one of the effective measure to control the cold rolling texture, which is a main governing factor for the formation of recrystallization texture, the applicability of the groove-rolling on the texture control of grain oriented silicon steels has been studied [1 4]. It was clarified that the groove-rolling was effective for the formation of $\{100\}<011\rangle$ secondary recrystallization texture.

This paper describes the influence of cold rolling with grooved rolls on the formation of both the cold rolling and the primary recrystallization textures of steel sheets. The groove-rolling is different from the normal flat rolling regarding the following functions, $i, e$, sheet is put under a great shearing deformation which is tilted periodically around rolling direction during the grooverolling, and sheet is deformed with mass flow toward transverse direction during following flattening. Then, the investigation was carried out to clarify the substantial effect of the groove-rolling on the texture formation of the steel sheet.

\section{EXPERIMENTAL PROCEDURE}

Extra low carbon Al-killed steel was received as $2.0 \mathrm{~mm}$ thick hot rolled band after high temperature coiling. The chemical composition of the steel used in this study is shown in Table 1. 
Table 1 Chemical composition of steel used. (wt 8 )

\begin{tabular}{ccccccc}
\hline $\mathrm{C}$ & $\mathrm{Si}$ & $\mathrm{Mn}$ & $\mathrm{P}$ & $\mathrm{S}$ & sol.Al & $\mathrm{N}$ \\
\hline 0.0022 & 0.76 & 0.34 & 0.092 & 0.003 & 0.27 & 0.0016 \\
\hline
\end{tabular}

The $2.0 \mathrm{~mm}$ thick, $150 \mathrm{~mm}$ wide and $1000 \mathrm{~mm}$ long specimens were cold rolled up to 5 to $55 \%$ with 1 to 6 passes under forward and backward tension by using two types of grooved rolls set in the 4-high experimental mill with lubricant. The shape of grooved rolls and the dimensions of the grooves used in this study are shown in Fig.1 and Fig.2, respectively. For the groove-rolling with type A, a grooved roll was set as upper roll. For the groove-rolling with type $B$, a pair of grooved rolls were used. The groove-rolled specimens were cold rolled by flat rolls to the thickness of $0.50 \mathrm{~mm}$ with a total reduction of $75 \%$ and subsequently annealed at $625^{\circ} \mathrm{C}$ to $850^{\circ} \mathrm{C}$ for $90 \mathrm{sec}$.

Measurements of texture at quarter layer of the specimen were carried out for each step in the treatments. The changes in pole intensities during recrystallization annealing were measured. For the specimens before and after annealing at $800^{\circ} \mathrm{C}$, the ODFs were calculated by the series expansion method $(1 \max =22$ ) by the Roe notation $[5,6]$ from (200), (110) and (211) pole figures measured by Mo-k $\alpha$ radiation.

\section{BESUIT AND DISCUSSION}

The typical optical microstructures observed at the transverse sections in the two types of groove-rolled specimens, which were cold rolled up to 16,32 and $55 \%$ by the grooved roll with type $A$, and up to 5, 17 and $33 \%$ by the grooved rolls with type $B$, are shown in Fig.3. With applying the groove rolling, the shape and the pitch corresponding to the grooves are transferred to the specimen and plastic flow lines of materials are undulated inside the specimen. With increase in the rolling reduction by grooved rolls, the materials at the surface layer markedly flow into the grooves on the roll surface.

As shown in Fig.4, the undulated plastic flow lines formed in the materials by cold rolling with grooved rolls are retained even after the flattening. After recrystallization annealing, however, marked differences in the microstructures are hardly observed between the groove-rolled specimens and the conventionally cold rolled specimens.

Figure 5 shows the effect of groove-rolling on the changes in (200) and (222) pole intensities during recrystallization annealing which were measured at surface and quarter layer of the thickness direction. The texture of groove-rolled specimen (type A) is composed of higher (200) and lower (222) pole intensities as compared with the conventionally cold rolled specimen not only after cold rolling but also during recrystallization annealing.

Figure 6 shows the changes in (200) and (222) pole intensities of the groove-rolled specimen (type B) as a function of groove-rolling reduction measured both after flattening and after recrystallization annealing at $800^{\circ} \mathrm{C}$. With the increase in the groove-rolling reduction, (200) intensities increase and (222) intensities decrease after annealing as well as after flattening. These results indicate that the changes in the textures of the groove-rolled specimen are affected by the change in mass flow toward transverse and normal direction during cold rolling caused by increase in the groove-rolling reduction as shown in Fig. 3 and Fig. 4 . 
The ODFs were analyzed in order to obtain more detailed information on the difference in the texture between the groove-rolled specimen and conventionally cold rolled specimen. Figure 7 shows the ODFs on $\phi=45 \mathrm{deg}$. section showing cold rolling texture. In both type $A$ and type $B$, the specimens were cold rolled by grooved rolls with the same reduction of approximately 33\%. The cold rolling texture of conventionally cold rolled specimen can be described by a strong $<111>/ / N D$ fiber texture and a strong $<110>/ /$ TD fiber texture. The preferred orientations in this texture are $\{111\}<112\rangle$ and $\{112\}<111\rangle$. With respect to the textures of groove-rolled specimens, while one of the preferred orientations developed by groove-rolling with type $A$ is the same $\{111\}\langle 112\rangle$, which is weakened, the peak of orientation density near $\{112\}<111>$ divides up into two peaks at $\{100\}<011\rangle$ and near $\{111\}<112\rangle$. In the case of type $B$, this tendency occurs more clearly in the cold rolling texture and a strong $\langle 100\rangle / / \mathrm{ND}$ fiber texture is observed. The preferred orientations are $\{111\}<112\rangle$ and $\{100\}<011\rangle$, which are caused by division of the peak of orientation. These marked differences in the texture can be explained in terms of the acceleration of the lattice rotation around $\langle 110\rangle$ axis which is parallel to the transverse direction as well as rolling direction by cold rolling with grooved rolls and following flattening, as can be seen in Fig. 8 .

With the change in the cold rolling texture, the primary recrystallization texture of the groove-rolled specimen is composed of lower $\{111\}\langle 110\rangle$ and higher $\{100\}\langle 0 \mathrm{vw}\rangle$ components by comparison with the texture of the conventionally rolled specimen, as shown in Fig.9. This results account for the decrease in nucleation frequency of $\{111\}<110\rangle$ grains and the difference of recrystallization rate depending on the grain orientation.

In order to confirm the influence of chemical composition of the specimen on the texture formation by groove-rolling, a similar experiment was conducted for the pure iron. The chemical composition of the specimen used is given in Table 2. Figure 10 shows the (200) and (222) pole intensities of the pure iron during recrystallization annealing. This results indicate the same tendency as the results obtained from the extra low carbon steel, which was shown ir Fig.5. It is concluded from these results that the influence of groove-rolling on the texture formation is not affected by the chemical composition of the specimen.

Table 2 Chemical composition of pure iron used. (wt

\begin{tabular}{ccccccc}
\hline C & Si & Mn & P & S & sol.Al & N \\
\hline 0.0015 & tr. & 0.02 & 0.001 & 0.004 & 0.001 & 0.0020 \\
\hline
\end{tabular}

\section{CONCLUSION}

In comparison with the cold rolling texture of the specimen conventionally flat rolled, the texture of the specimens subjected to the groove-rolling is composed of lower $\{111\}<112\rangle$ and higher $\{100\}<011\rangle$ components. This is attributed to the acceleration of the lattice rotation around $\langle 110\rangle$ axis which is parallel to the transverse direction as well as rolling direction by cold rolling with grooved rolls and following flattening. With the change in the cold rolling texture, the primary recrystallization texture of the groove-rolled specimen showed lower $\{111\}\langle 110\rangle$ and higher $\{100\}<0 v w\rangle$. 


\section{REEERENCE}

1. M.Kumazawa, Y.Nakagawa and T.Sekine, Tetsu-to-Hagane, 63, 1828 (1977)

2. M.Kumazawa, K. Iwayama and Y.Suga, Tetsu-to-Hagane, 63, 1838 (1977)

3. M.Kumazawa, Y.Nakagawa, O.Honjo and T.Sekine, Tetsu-to-Hagane, 63, 2335 (1977)

4. T.Wada, K.Kuroki and K.Iwayama, Tetsu-to-Hagane, 70, 2065 (1984)

5. R.J.Rœe, J.Appl.Phys., 36, 2024 (1965)

6. R.J.Rœ, J.Appl.Phyc., 37, 2069 (1966)

Type A: Groove/Flat Type $\mathrm{B}_{;}$: Groove/Groove

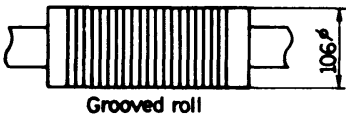

Figure 1

Schematic illustration of the grooved roll.

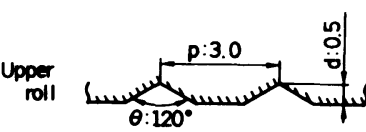

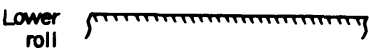

Figure 2 Dimensions of and arrangement of grooved rolls. (a)

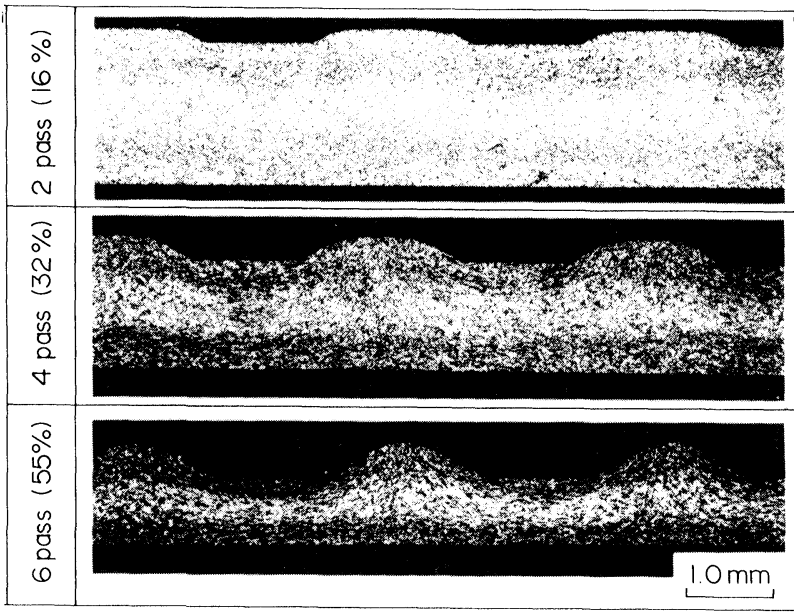

(b)

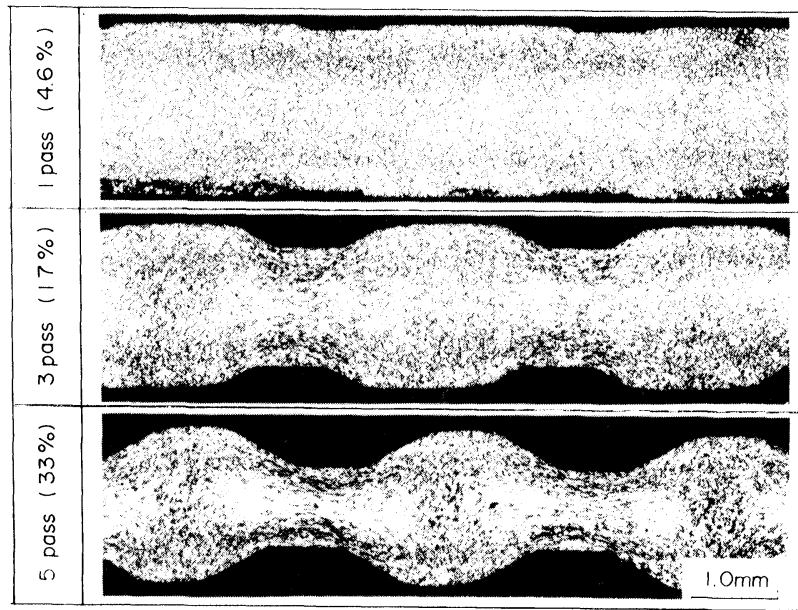

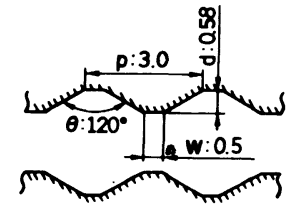

ace
Figure 3

Changes in cross-sectional microstructures of the specimens cold rolled with grooved rolls.

(a) Groove-rolling type A (groove/flat)

(b) Groove-rolling type B (groove/groove) 


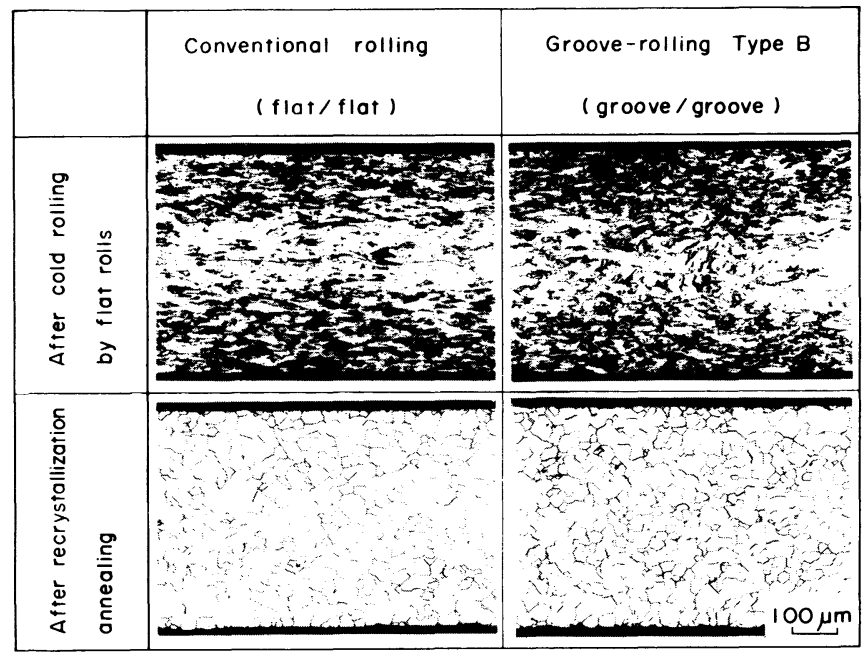

Figure 4

Cross-sectional microstructures of the specimens after cold rolling by flat rolls and after recrystallization annealing.

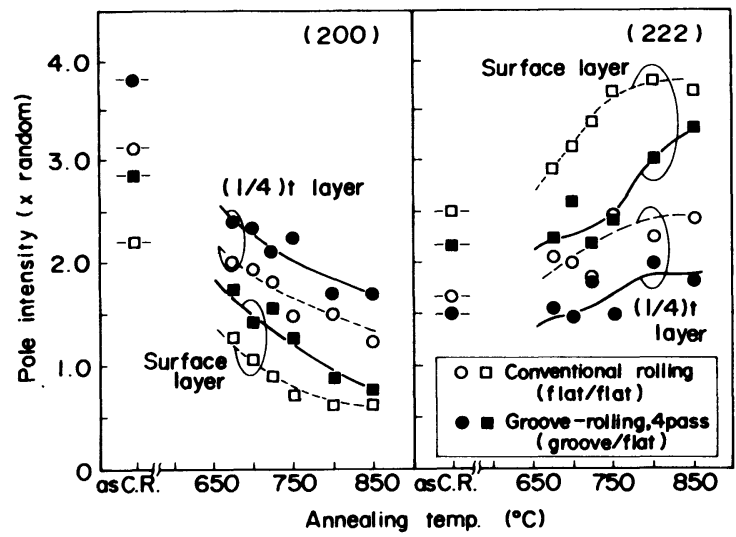

Figure 5

Effect of groove-rolling on the changes in pole intensities at the surface and at quarter of the thickness during recrystallization annealing.

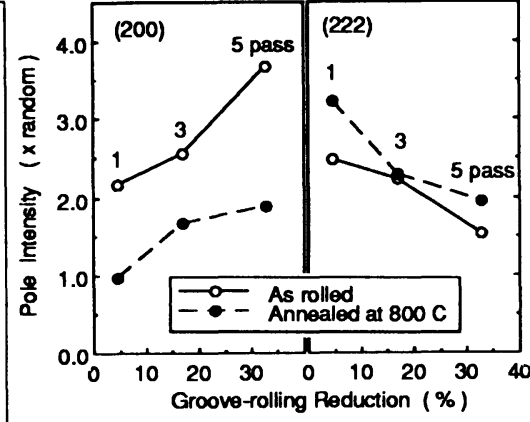

Figure 6

Effect of groove-rolling reduction on pole intensities for the specimens after flattening and after recrystallization annealing at $800^{\circ} \mathrm{C}$. (a)

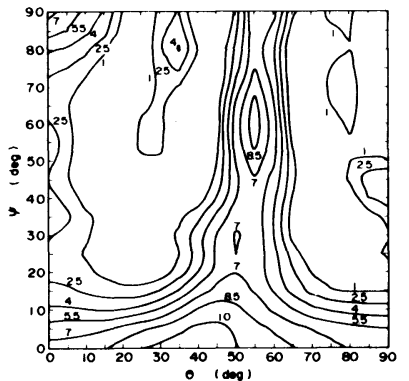

(b)

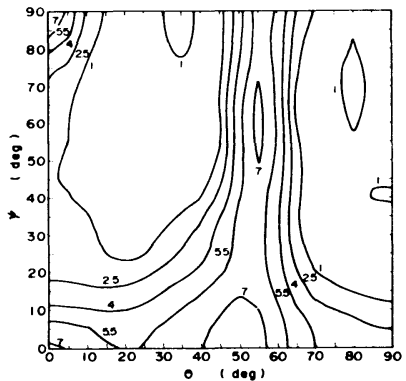

(c)

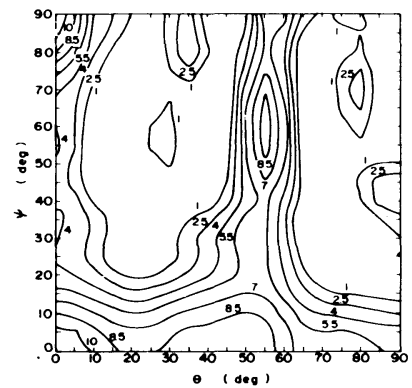

Figure 7 ODFs on $\phi=45 \mathrm{deg}$. section for the specimens after conventional cold rolling and after flattening.

(a) Conventional rolling

(b) Groove-rolling type A (groove/flat)

(c) Groove-rolling type B (groove/groove) 
(a)

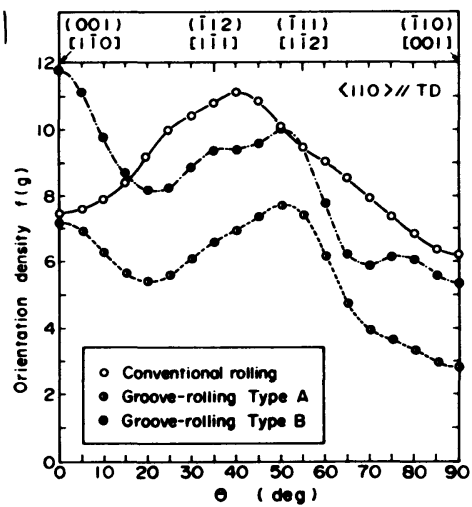

(b)

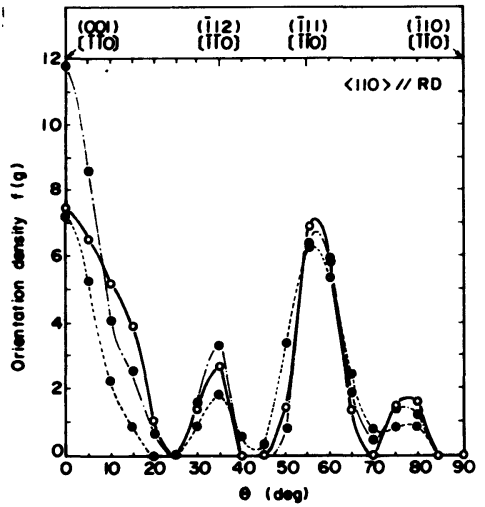

Figure 8 Orientation densities along the following lines in the Euler space for the specimens after conventional cold rolling and after flattening.

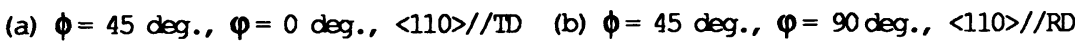

(a)

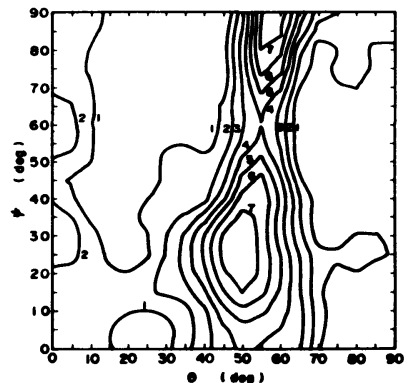

(b)

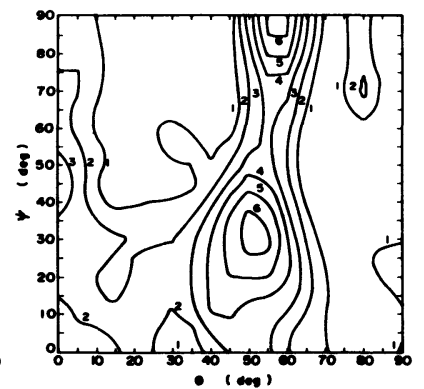

(c)

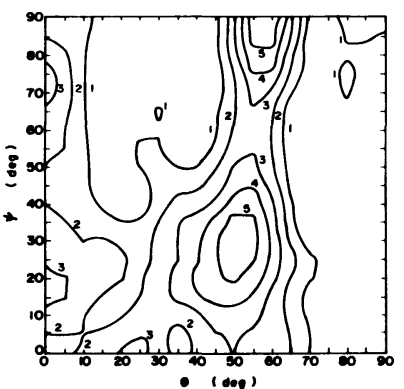

Figure 9 CDFs on $\phi=45 \mathrm{deg}$. section for the specimens after recrystallization annealing at $800^{\circ} \mathrm{C}$.

(a) Conventional rolling

(b) Groove-rolling type A (groove/flat)

(c) Groove-rolling type B (groove/groove)
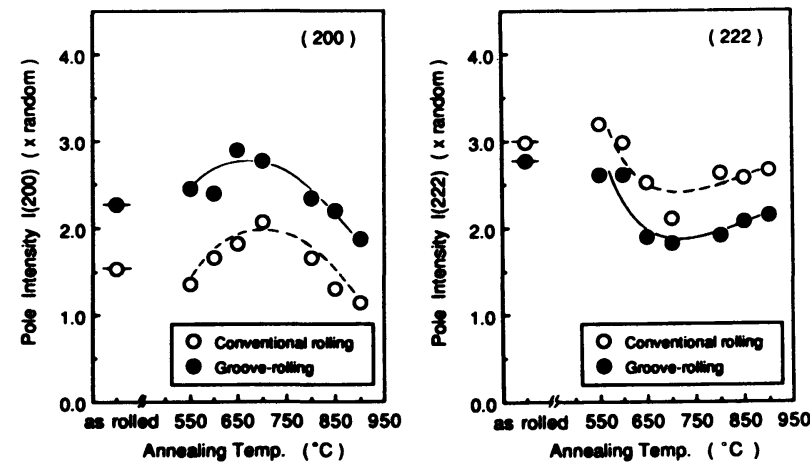

Figure 10 Effect of groove-rolling on the changes in pole intensities of pure iron curing recrystallization annealing. (Type A, 5 pass ) 